
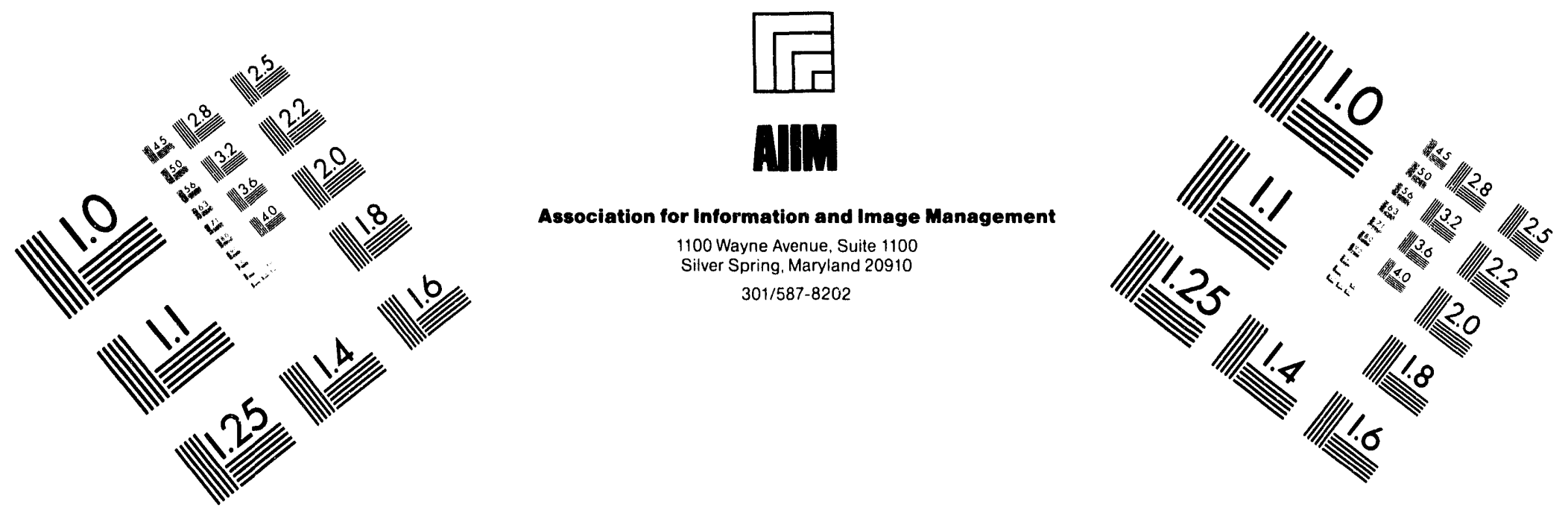

\title{
Centimeter
}

$\begin{array}{llllllllllllllll}1 & 2 & 3 & 4 & 5 & 6 & 7 & 8 & 9 & 10 & 11 & 12 & 13 & 14 & 15 & \mathrm{~mm}\end{array}$

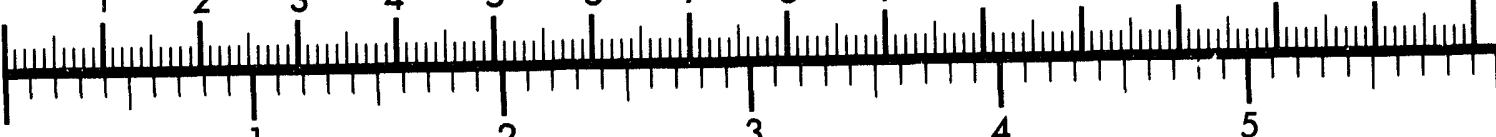
Inches
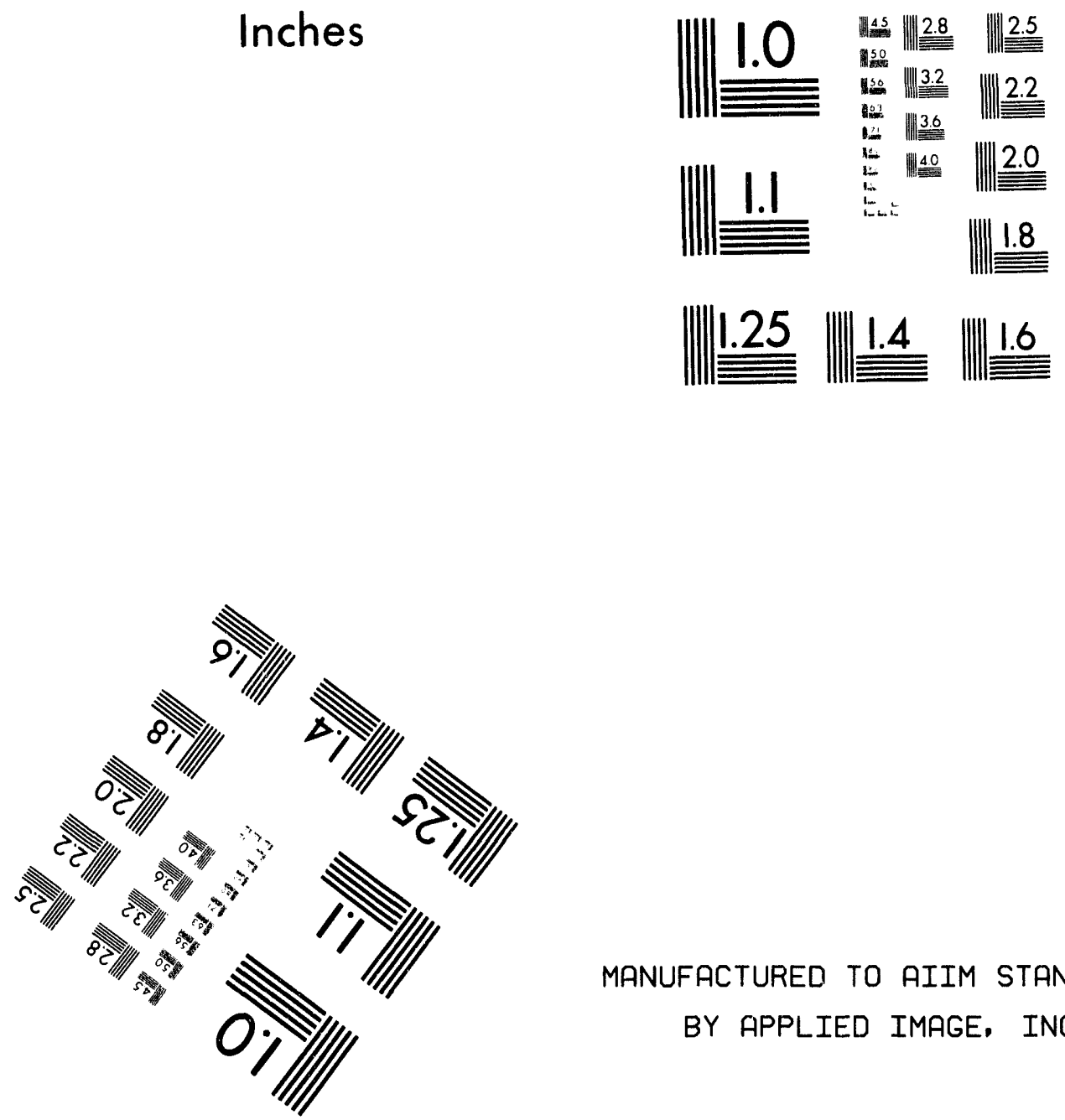

MANUFACTURED TO AIIM STANDARDS BY APPLIED IMAGE, INC.

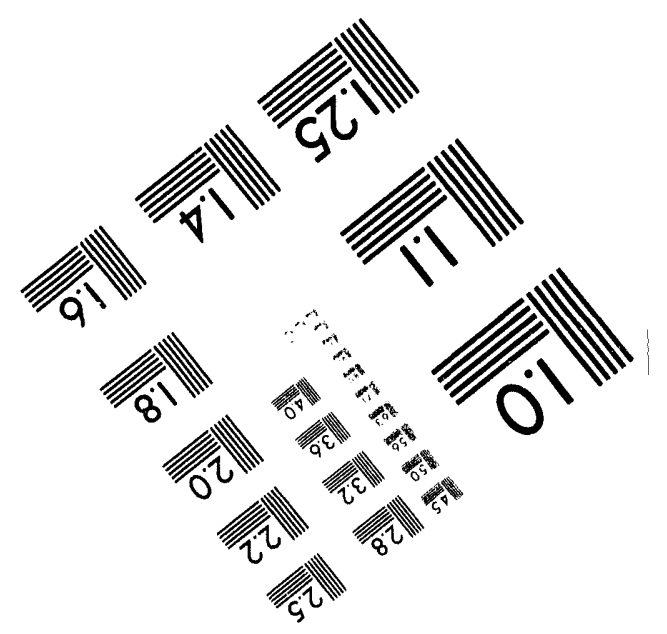



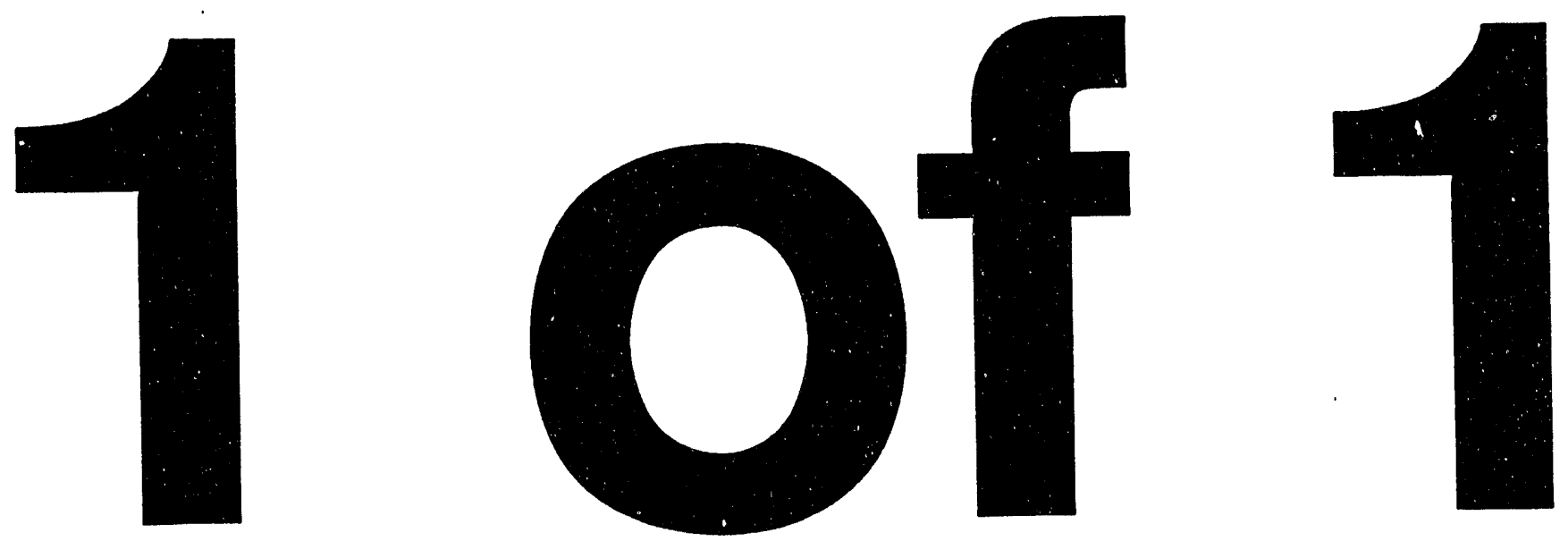
DOE/ER52147- 7

\section{MICROWAVE GENERATION \\ FOR \\ MAGNETIC FUSION ENERGY APPLICATIONS}

Progress Report

May 1, 1993 to May 1, 1994

Task A: Free Electron Lasers with Small Period Wigglers

\section{Principle Investigaturs}

T. M. Antonsen Jr., W. W. Destler, V. Granatstein, B. Levush

Task B: Theory and Modeling of High Frequency, High

Power Gyrotron Operation

\section{Principle Investigators}

T. M. Antonsen Jr., B. Levush

Institute for Plasma Research and

Department of Electrical Engineering

University of Maryland

College Park, MD 20742

\section{May 1994}

PREPARED FOR THE U.S. DEPARTMENT OF ENERGY

UNDER CONTRACT NUMBER DEFG05-87ER52147

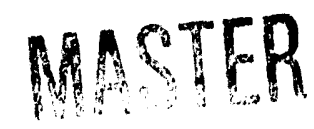




\section{Task A: Free Electron Lasers with Small Period Wigglers}

\section{DISCLAIMER}

This report was prepared as an account of work sponsored by an agency of the United States Government. Neither the United States Government nor any agency thereof, nor any of their employees, makes any warranty, express or implied, or assumes any legal liability or responsibility for the accuracy, completeness, or usefulness of any information, apparatus, product, or process disclosed, or represents that its use would not infringe privately owned rights. Reference herein to any specific commercial product, process, or service by trade name, trademark, manufacturer, or otherwise does not necessarily constitute or imply its endorsement, recommendation, or favoring by the United States Government or any agency thereof. The views and opinions of authors expressed herein do not necessarily state or reflect those of the United States Government or any agency thereof. 


\section{INTRODUCTION}

The leading millimeter wave generator being developed for electron cyclotron resonance applications in the magnetic fusion program is the gyrotron oscillator. This fixed-frequency source is being developed with the goal of achieving $1 \mathrm{MW}$ cw output power. Some stepwise frequency agility may be achieved in such devices, but they are clearly not capable of continuously variable frequency variation. Free electron laser (FEL) amplifiers, therefore, may prove an attractive alternative as ECR sources since they have the potential to operate with $\mathrm{cw}$ powers per amplifier much greater than $1 \mathrm{MW}$ and can be continuously tuned in frequency by simply varying the electron beam energy.

Experiments at the Livermore National Laboratory, for example, have shown the feasibility of high pulsed power, high efficiency, millimeter-wave FEL amplifiers driven by electron beams of several $\mathrm{MeV}$ energy. The research undertaken under Task $\mathrm{A}$ of this program strives to develop high average power FEL at voltages below $1 \mathrm{MV}$ allowing for smaller and less costly power supplies. To achieve operation of an FEL at frequencies in the range 100-150 Ghz using these relatively modest electron energies, we have been utilizing the use of small period $\left(\lambda_{w}\right.$ $\sim 1 \mathrm{~cm}$ ) planar wiggler magnets together with sheet electron beams. The sheet beam geometry allows for an FEL interaction region in the form of a narrow slit with high wiggler field at the center plane where the electrons are concentrated. The total current and power may then be increased without making current density excessive by increasing the wide dimension of the sheet beam. Sheet beam FEL parameters for the Proof-of-Principle FEL experiment currently under investigation in our laboratory, and an ITER relevant FEL design are shown in Table 1.

During the past year we have made substantial progress in these studies. Linear amplification experiments employing a 56 period untapered wiggler have been conducted, and substantial small signal gain has been observed at $94 \mathrm{Ghz}$ over a wide range of experimental conditions consistent with the predictions of one-dimensional numerical simulations. In section 2 below these studies are summarized, and preliminary results of a new experiment utilizing a 1 kilowatt input driver at $85 \mathrm{Ghz}$ to explore large signal amplification in the linear regime are also presented. 
Table 1: FEL amplifier design parameters. (Input rf power assumed to $1 \mathrm{~kW}$.)

ITER Relevant Proof-of-Principle

FEL Parameters

Design Experiment

Frequency, $f$

$150 \mathrm{GHz}$

$94 \mathrm{GHz}$

Voltage, $\phi_{H V}$

$860 \mathrm{kV}$

$470 \mathrm{kV}$

Current, $I_{b}$

$30 \mathrm{~A}$

$10 \mathrm{~A}$

Beam thickness, $y_{b}$

$3 \mathrm{~mm}$

$1 \mathrm{~mm}$

Beam width, $x_{b}$

$3 \mathrm{~cm}$

$2 \mathrm{~cm}$

Waveguide height, $b$

$7.5 \mathrm{~mm}$

$3.2 \mathrm{~mm}$

Waveguide width, $a$

$4 \mathrm{~cm}$

$4 \mathrm{~cm}$

Wiggler period, $\lambda_{w}$

$1.5 \mathrm{~cm}$

$0.96 \mathrm{~cm}$

Peak flux density (untapered wiggler), $B_{w 0}$

$7.0 \mathrm{kG}$

$5.1 \mathrm{kG}$.

Wiggler parameter, $a_{w 0}$

0.98

0.46

Linear gain (untapered wiggler)

$0.44 \mathrm{~dB} / \mathrm{cm}$

$0.47 \mathrm{~dB} / \mathrm{cm}$

Length of untapered wiggler

$63 \mathrm{~cm}$ $50 \mathrm{~cm}$

Saturated power at end of untapered wiggler

$620 \mathrm{~kW}$

$180 \mathrm{~kW}$

Length of tapered wiggler

$66 \mathrm{~cm}$

$54 \mathrm{~cm}$

Output power

$5 \mathrm{MW}$

$0.4 \mathrm{MW}$

Intrinsic FEL efficiency

$19 \%$

$8.5 \%$

Maximum RF wall heating

$1.1 \mathrm{~kW} / \mathrm{cm}^{2}$

Total efficiency (with $80 \%$ energy recovery) $54 \%$

Main power supply voltage

(with $80 \%$ energy recovery), $\phi_{\mathrm{LV}}$

$309 \mathrm{kV}$ 


\section{TECHNICAL PROGRESS}

\subsection{Small-Signal Amplification Studies at $94 \mathrm{Ghz}$}

The basic experimental configuration used for these studies is shown in Fig. 1. A sheet electron beam $1 \mathrm{~mm} \times 10 \mathrm{~mm}$ in cross section is injected into an untapered planar magnetic wiggler 56 periods in length, with wiggler period $9.6 \mathrm{~mm}$. Because an electromagnet wiggler is used, magnetic field amplitude at the center of the $3 \mathrm{~mm} \times 2 \mathrm{~cm}$ beam propagation channel is continuously variable over the range $0-6$ kilogauss. Typical electron beam energy and current are in the ranges $500-580 \mathrm{keV}$ and 2-20 A, respectively. The input if source was a low power (1-10 W) extended interaction oscillator operating at $94 \mathrm{Ghz}$.

An extensive study of wave amplification as a function of beam energy and current and wiggler field amplitude has been conducted and the results compared to the predictions of a onedimensional numerical simulation of the experiment. These results are detailed in an invited paper presented at the APS/Division of Plasma Physics Meeting to be published in a special issue of the Physics of Plasmas in June 1994 (results of earlier amplification studies have recently been published in Applied Physics Letters). A typical result from that study is shown in Fig 2. Excellent agreement between the experimental results and the predictions of the simulation is evident, and small-signal gains as high as $17-19 \mathrm{~dB}$ have been observed. These results are entirely consistent with those expected from the Proof-of-Principle experiment, and clearly illustrate the potential of such simple FEL amplifiers for high-gain operation at millimeter-wave frequencies.

\subsection{Large-Signal Amplification Studies at $85 \mathrm{Ghz}$}

Although the small-signal gain experimental results are very encouraging, a second experiment has been recently constructed to investigate whether the effective gains observed using the 1-10 Watt EIO input source at $94 \mathrm{Ghz}$ can be duplicated at higher input power levels. For this second experiment, a high power pulsed ElO operating at $85 \mathrm{Ghz}$ at power levels up to 1 kilowatt was obtained on loan from the Naval Research Laboratory, and linear amplification studies utilizing the same 56 period untapered wiggler have commenced. 


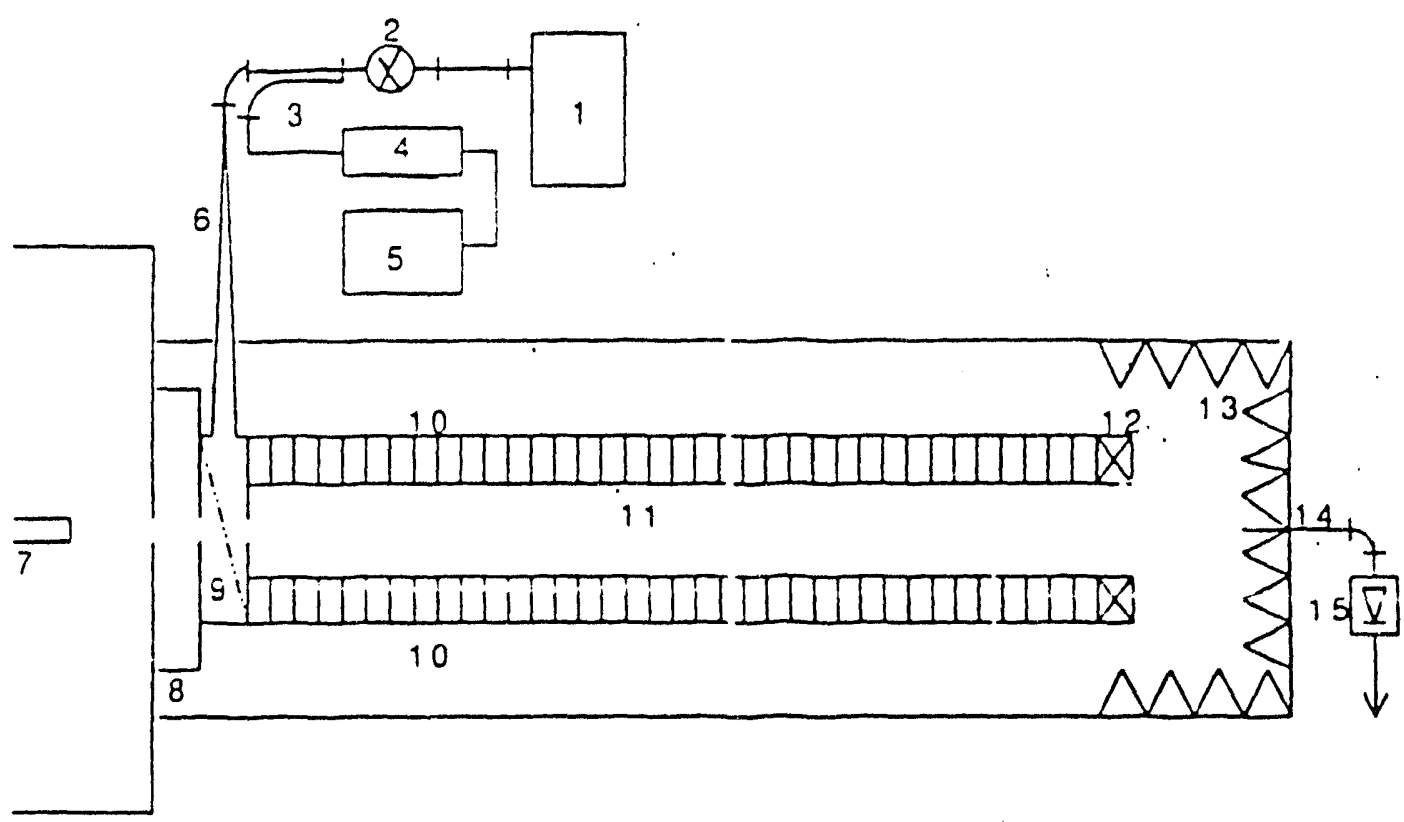

Figure 1: FEL amplifier experiment configuration: 1) EIO tube; 2) fixed altcnuator, $-20 \mathrm{~dB}$; 3) directional coupler, -.20 dB; 4) sensor; 5) power meter; 6) waveguide taper; 7) cathode; 8) two slot anode; 9) miter bend; 10) planar wiggler, 56 periods; 11) amplifier waveguide; 12) Rogowski coil; 13) absorption material; 14) waveguide antenna. w-band; 15) microwave dinde. 
To date, input if powers ranging from 1 watt to 500 watts have been injected into the FEL amplifier, and gains as high as $7 \mathrm{~dB}$ have been achieved independent of $\mathrm{rf}$ input power level. Our initial failure to reproduce the higher gains observed in the earlier experiment are currently attributed to our failure to reproduce the favorable beam injection and propagation conditions achieved in the earlier experiments. Since the injected electron beam is generated in a high power field emission diode and collimated using a double slit anode configuration, small changes in the operating conditions of the driving pulse line accelerator or input wiggler magnetic field profile can result in large changes in observed beam properties. We are presently modifying the experiment to more closely approximate the conditions obtained in the previous higher gain experiments. In any event, it is clear from these results that observed gain is not a function of input $\mathrm{rf}$ power at least up to these power levels.

\section{TASK A PUBLICATIONS}

1. W. W. Destler, S. Cheng, Z. X. Zhang, T. M. Antonsen, Jr., V. L. Granatstein, B. Levush, and J. Rodgers, "First Operation of a Wiggler-Focused, Sheet Beam Free Electron Laser Amplifier", Phys. Plasmas (to be published).

2. J. H. Booske, M. A. Basten, A. H. Kumbasar, T. M. Antonsen, Jr., S. W. Bidwell, Y. Carmel, W. W. Destler, V. L. Granatstein, and D. J. Radack, "Periodic Magnetic Focusing of Sheet Electron Beams", Phys. Plasmas (to be published).

3. Z-X. Zhang, W. W. Destler, V. L. Granatstein, T. M. Antonsen, Jr., B. Levush, J. Rodgers, and S. Cheng, "Experimental Realization of Millimeter-Wave Amplification by a Sheet Beam Free Electron Laser", Applied Physics Letters, 64, 1439-1441 (1994).

4. Z. X. Zhang, V. L. Granatstein, W. W. Destler, B. Levush, T. M. Antonsen, Jr., J. Rodgers, and S. Cheng, "First Operation of a $94 \mathrm{GHz}$, Sheet Beam, FEL Amplifier", Nucl. Inst. Meth Res. A341, 76-79 (1994). 


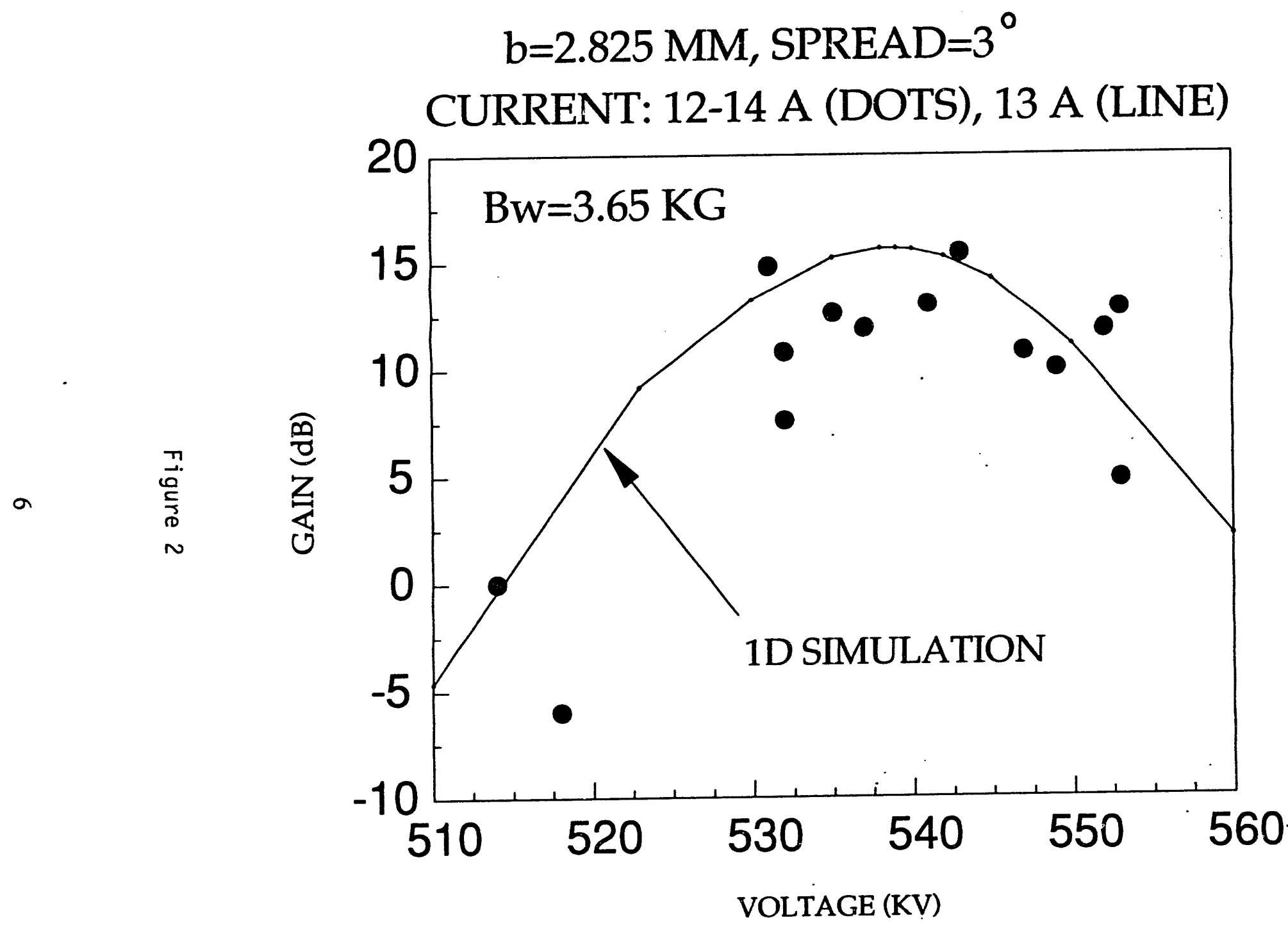

FILE: GAIN62.PSG 
Task B: Theory and Modeling of High Frequency, High Power Gyrotron Operation 


\section{Progress in Gyrotron Theory and Modeling, Task B}

A number of important issues in the development of high power gyrotrons center on the ability to predict and improve the performance of various cavity designs. These issues include the elimination of mode competition, the optimization of efficiency, the minimization of wall loading, the accessibility of optimum operating conditions during start-up, and the elimination of mode conversion at various points in the cavity. Also included is the issue of beam quality which can strongly affect the operation of a device.

Our group has undertaken a theoretical study of these issues which we describe below. Our main tool for these studies is the multimode simulation code, MAGY, which has successfully predicted the occurrence of mode competition in the MIT simple tapered cavity experiments. This code can has been modified to determine the output mode purity of gyrotrons such as the one at General Atomics. Additionally, we have made provisions to the code that allow it to accept as input data the experimentally determined beam perpendicular velocity distribution function.

\section{Technical Progress}

1. Varian, $110 \mathrm{GHz}$ TE 22,6 experiment: We have modeled three cavities proposed for this experiment. The first two cavities exhibited mode competition from a neighboring TE 23,6 mode at high currents. The third design, incorporating our suggested changes, showed no mode competition at the proposed operating conditions. Parameters for specific simulations and results are shown in table 4.1 and fig. 4.1 respectively. This cavity is currently under test at Varian. 
Varian $110 \mathrm{GHz} \mathrm{TE}_{22,6}$ Cavity Simulation Results

Single mode simulations

\begin{tabular}{|l|ccccc|}
\hline \hline Beam Voltage (kV) & 80 & 80 & 80 & 80 & 80 \\
Pitch Angle & 1.5 & 1.5 & 1.5 & 1.5 & 1.5 \\
Beam Current (A) & 30 & 30 & 40 & 40 & 40 \\
$3_{\perp}$ spread (\%) & 0 & 13.4 & 0 & 16.4 & 7.4 \\
Frequency (GHz) & 109.93 & 109.93 & 109.92 & 109.92 & 109.93 \\
Optimal Power (kW) & 1225.9 & 795.7 & 1748.0 & 1023.1 & 1491.8 \\
Optimal Efficiency (\%/) & 51.1 & 33.2 & 54.6 & 32.0 & 46.6 \\
Hot Q & 1380 & 1290 & 1300 & 1250 & 1250 \\
Max. Wall-loading $\left(\mathrm{kW} / \mathrm{cm}^{2}\right)$ & $0.82 \tau$ & 0.461 & 1.06 & 0.564 & 0.859 \\
Reflected Electrons $(\%)$ & 0 & 1.09 & 0 & 3.39 & 0 \\
\hline
\end{tabular}

Table 4.i 
Multimode simulations of

Varian cavity $110 \mathrm{GHz}$

$I=30$ Amps $V=80 \mathrm{kV}$

$\alpha=1.5$

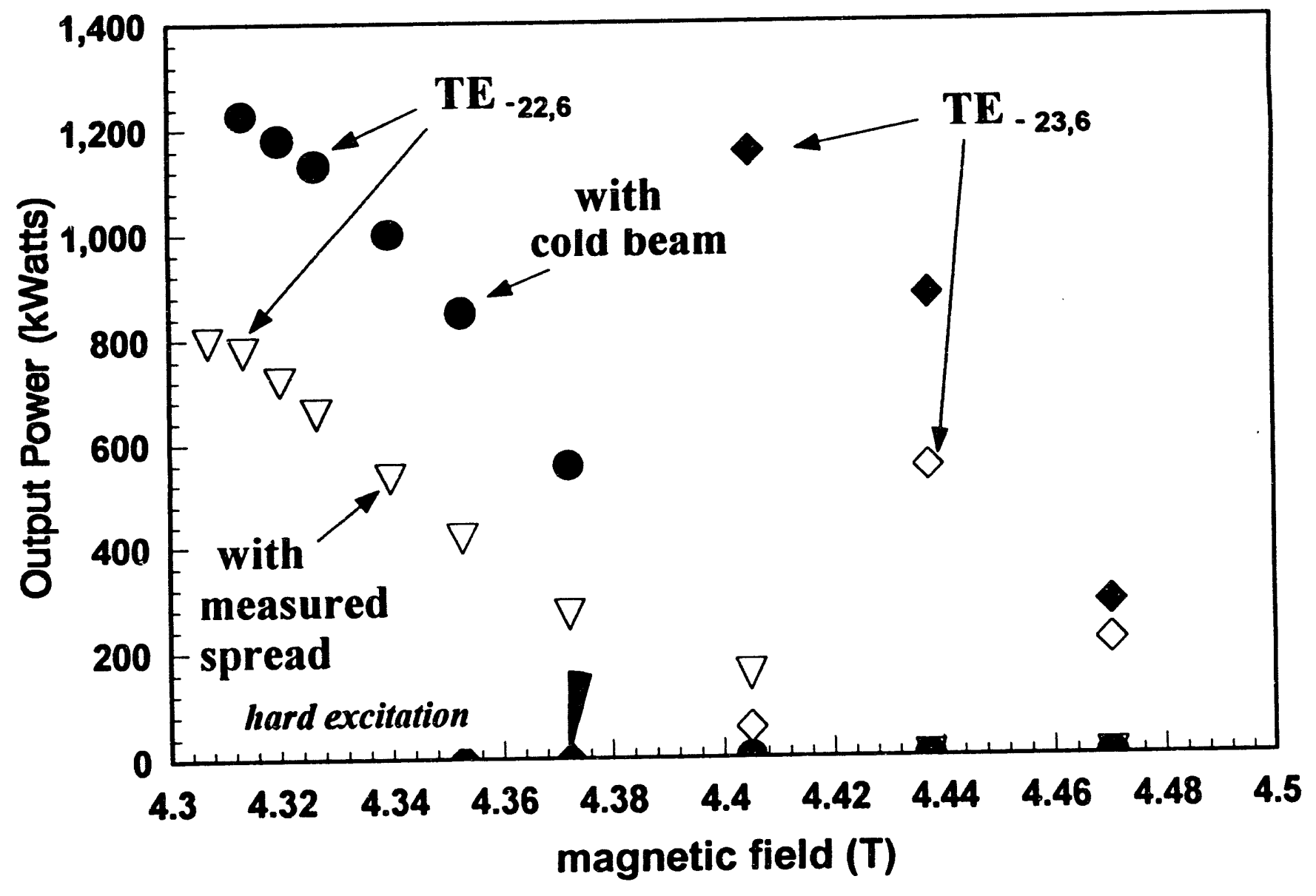


Additionally, we have simulated two start-up scenarios for this experiment. The first corresponds to desired scenario in which the beam voltage rises slowly with time. In this case the operating point is easily accessed. The second scenario corresponds to the existing experimental conditions in which the beam is at full voltage when initiated. Here access to the operating point is more difficult, but still possible due to a cooperative mode interaction with the TE 21,6 mode. We believe this latter scenario is probably not reliable, and future designs should attempt to reach the operating point using the first scenario.

2. Velocity Spread: We have modeled the effect of perpendicular velocity spread on the operation of a number of gyrotrons, including those at MIT and Varian. The distribution of perpendicular velocities used in the simulations is based on the experimental measurements performed at MIT. These experiments suggested that the relative perpendicular velocity spread could be as high as $\pm 15 \%$, which is about twice the previously estimated value. Our simulations showed that this level of velocity spread in the MIT tapered cavities would degrade efficiency to a point below that which was measured. The experimental results were consistent with a perpendicular velocity spread of about $\pm 10 \%$. This is still a large spread, and there are indications from the simulations that at this level of spread, performance is sensitive to details of the distribution function. Of two MIT cavities driven by the same beam, we noted that the higher $\mathrm{Q}$ cavity seemed to be less affected by velocity spread than the lower $Q$ cavity. This knowledge will be useful in the design of future devices.

3. $170 \mathrm{GHz}$ ITER design: We participated in the US team's design of a $170 \mathrm{GHz}$ TE30,9,1 gyrotron for ITER. Our investigations focused on mode competition and velocity spread. Multimode simulations of the 170 $\mathrm{GHz}$ cavity design show that the $\mathrm{TE}_{30,9,1}$ mode is able to grow from noise in competition with the $\mathrm{TE}_{29,9,1}$ and $\mathrm{TE}_{31,9,1}$ modes and ultimately suppress these modes resulting in a single frequency output. Parameters for these simulations are shown in table 4.2 


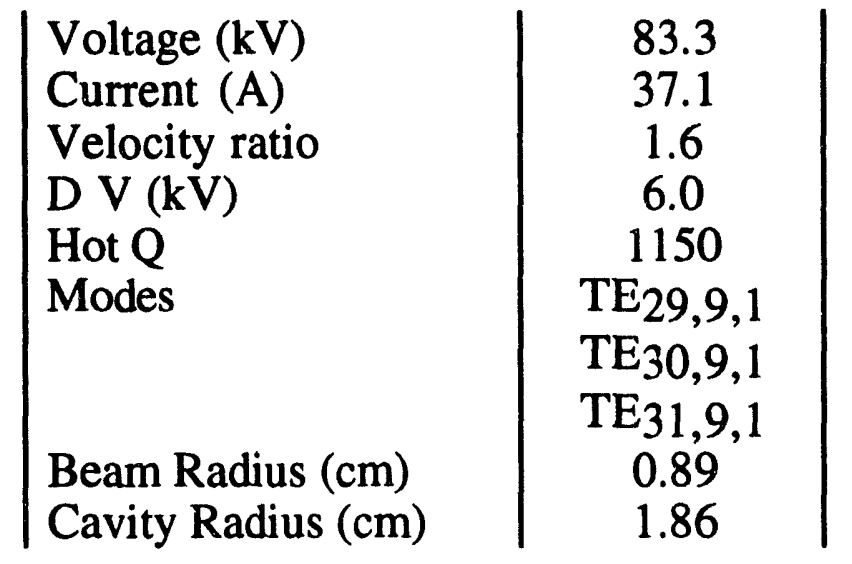

Table 4.2 -- $170 \mathrm{GHz}$ Multimode simulation parameters

With regard to beam quality it was found that perpendicular velocity spreads much above $\pm 10 \%$ will quickly have a detrimental effect on the efficiency. For spreads of about $\pm 8 \%$, single mode operation with an efficiency of $35 \%$ should be possible. These result are displayed in fig. 4.2 .

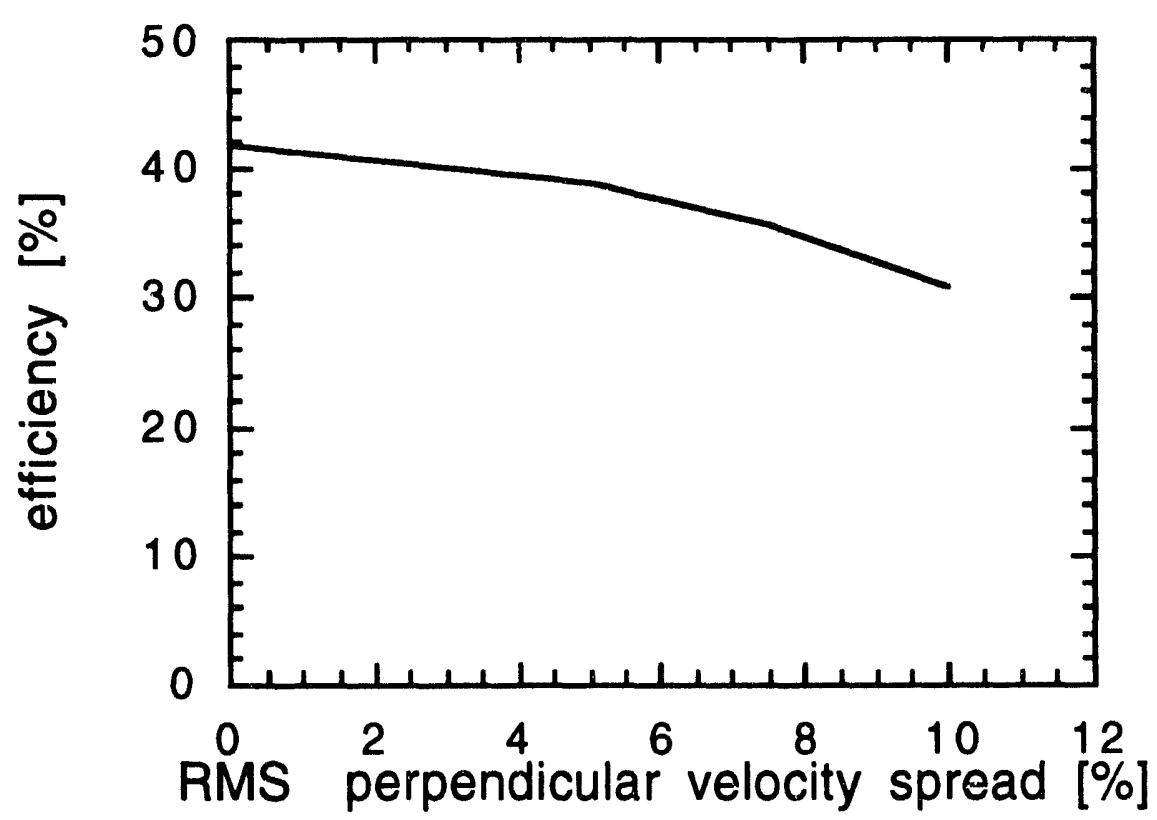

Fig. 4.2 efficieny versus velocity spread for $170 \mathrm{GHz}$ design. 
4. Harmonic mode competition: We have developed a general theory and simulation model to study the competition between modes at different harmonics of the cyclotron frequency. Such a theory is useful in the event that ultrahigh frequency sources are needed but the strength of the magnetic field is limited. We have found a number of situations were high efficiency operation at a harmonic of the cyclotron frequency is possible due to the suppression of the fundamental. This work comprises the Ph. D. dissertation of one our graduate students, Girish Saraph.

In summary, the design of high power gyrotrons for fusion applications requires a strong theoretical and modeling base. The efforts of our group are aimed at providing this base.

\section{Task B Publications}

"Studies of the Self-Consistent Field Structure in a Quasi-optical

Gyrotron," T. M. Antonsen, Jr., A. Bondeson, M. Roulin, and M. Q. Tran, Phys. Fluids B5, 3798-3807(Oct. 1993).

"Nonlinear Theory of Stable, Efficient Operation of a Gyrotron at Cyclotron Harmonics," G. P. Saraph, T. M. Antonsen, Jr., G. S. Nusinovich, and B. Levush, Phys. Fluids B5, 4473-4485 (1993)

"Space Charge Instabilities in Gyrotron Beams," H. Li and T. M. Antonsen, Jr., Physics of: Plasmas 1, 337 (1994).

"Influence of sideband oscillations on gyrotron efficiency", W. C. Guss, M. A. Basten, K. E. Kreischer, R. J. Temkin, T. M. Antonsen Jr., S. Y. Cai, G. Saraph, and B. Levush, submitted to IEEE Trans. Plasma Sci.

"Mode competition and start-up in cylindrical cavity gyrotrons using highorder operating modes", D. R. Whaley, M. Q. Tran, T. M. Tran, and T. M. Antonsen Jr., to be published IEEE Trans. Plasma Sci.

"Phase locking, amplification, and mode selection in an $85 \mathrm{GHz}$ quasioptical gyrotron", R. P. Fischer, A. W. Fliflet, W. M. Manheimer, B. Levush, T. M. Antonsen Jr., and V. L. Granatstein, Phys. Rev. Lett. 72, 2395 (1994) 

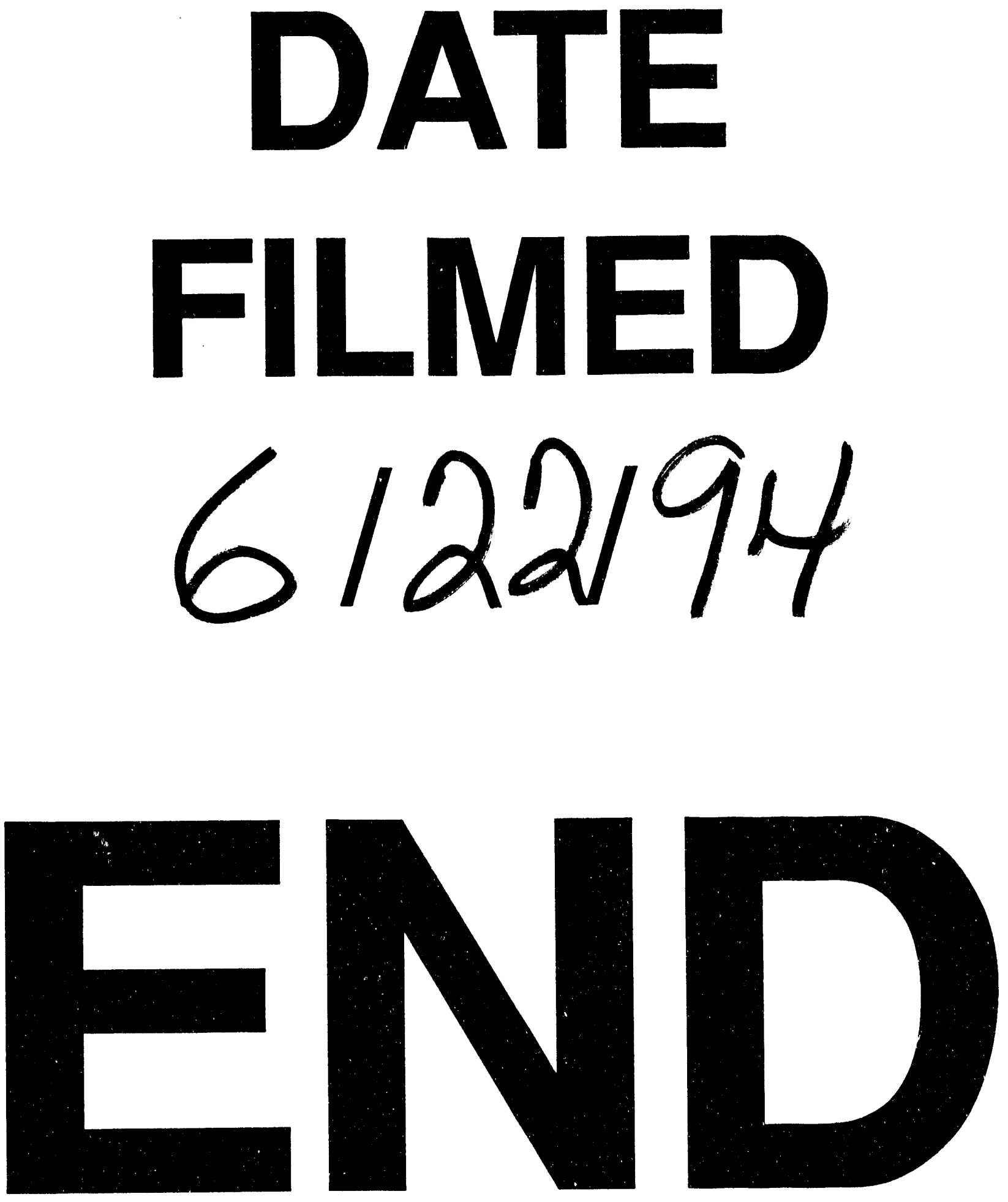


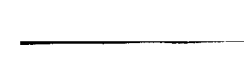

